\title{
Home versus hospital intravenous antibiotic therapy in the treatment of young adults with cystic fibrosis
}

\author{
M.N. Pond, M. Newport, D. Joanes, S.P. Conway
}

Home versus hospital intravenous antibiotic therapy in the treatment of young adults with cystic fibrosis. M.N. Pond, M. Newport, D. Joanes, S.P. Conway. CERS Journals Ltd 1994

ABSTRACT: We wanted to investigate whether home intravenous antibiotic treatment of pulmonary exacerbations of cystic fibrosis is as effective as treatment in hospital.

The case records of all patients attending the Leeds adult cystic fibrosis clinic were reviewed to identify those who had received home intravenous antibiotic treatment. All home treatments undertaken were included. For each home treatment, the temporally closest hospital treatment for that patient was then selected for comparison and the changes with treatment in peak expiratory flow rate (PEFR), forced vital capacity (FVC), forced expiratory volume in one second $\left(F E V_{1}\right)$, Creactive protein (CRP), plasma viscosity, total white cell count, absolute neutrophil count, total immunoglobulin G (IgG) concentration, chest X-ray score (Northern), clinical score, Shwachman-Kulczyki score and weight were analysed for differences between home treatment and hospital treatment. Fifty one paired home/hospital treatments in 25 patients were compared.

The improvement in total white cell count was found to be significantly greater in the hospital group, but the difference was very small. The improvements in absolute neutrophil count, and all the other measured variables, were the same in the two groups.

Treatment of exacerbations of cystic fibrosis at home or in hospital is, thus, equally effective given proper patient selection and adequate monitoring of the response to treatment.

Eur Respir J., 1994, 7, 1640-1644.
Regional Adult Cystic Fibrosis Unit, Seacroft Hospital, Leeds, UK.

Correspondence: S.P. Conway

Seacroft Hospital

York Road

Leeds LS14 6UH

UK

Keywords: Antibiotic

cystic fibrosis

home

hospital

therapy

Received: August 41993

Accepted after revision May 191994
Significant pulmonary disease occurs in the great majority of cystic fibrosis patients, manifested as a progressive decline in lung function punctuated by acute exacerbations. The predominant pathogen isolated from sputum in adults is Pseudomonas aeruginosa, with other pseudomonas species, Staphylococcus aureus and Haemophilus influenzae isolated less frequently. Although current evidence suggests that the bulk of pulmonary damage is caused by host immune responses rather than by direct bacterial mechanisms [1-3], the mainstays of treatment remain antibiotics and physiotherapy. There have been encouraging preliminary results with routine three monthly antipseudomonal chemotherapy, as opposed to treatment only at the time of clinical exacerbation [4].

The benefits of intensive hospital-based treatment must be weighed against the costs, both economic and in terms of inconvenience to the patient. In addition, there is a danger of cross-infection in the hospital environment. Home treatment minimizes these costs and risks and has been facilitated by continuing improvements in intravenous cannulae, totally implantable vascular access systems (TIVAS) and drug delivery systems.
Nevertheless, it is important to be sure that home treatment is as effective as hospital treatment and that clinical improvement is not sacrificed for considerations of economy and convenience. The aim of this study was to audit the results of home therapy compared with in-patient therapy in young adults with cystic fibrosis using multiple, objective outcome measures.

\section{Methods}

\section{Study subjects and design}

All subjects were young adults (mean age 22 yrs, range 17-29 yrs) with cystic fibrosis, proven with positive sweat tests. All were chronically colonized with Pseudomonas aeruginosa.

The database of the Cystic Fibrosis Unit was reviewed to identify home treatments of pulmonary exacerbations that had been undertaken by the unit. For each treatment thus identified, the temporally closest hospital 
treatment for that patient was selected for comparison. Thus, patients acted as their own controls. Home and hospital treatments were then compared by analysing the improvement in the following variables, which were routinely measured at the start and end of a course of treatment: peak expiratory flow rate (PEFR), forced expiratory volume in one second $\left(\mathrm{FEV}_{1}\right)$, forced vital capacity (FVC), C-reactive protein (CRP), plasma viscosity, total white cell count, absolute neutrophil count, total immunoglobulin G (IgG), Northern chest X-ray score (unpublished scoring system, range 0 (unaffected) to 20 (maximal change)), clinical score [5], ShwachmanKulczyki score [6], and weight.

We consider arterial blood gas estimation to be too invasive for routine use. Daytime arterial oxygen saturation $\left(\mathrm{SaO}_{2}\right)$ may be normal despite nocturnal desaturation [7], measurement of which has been shown to be reproducible [8]. Consequently, we regard nocturnal $\mathrm{SaO}_{2}$ as the outcome measure of choice, but logistic constraints prevent its routine use in home intravenous therapy.

The accuracy of collection of sputum in the home setting is impossible to verify, and likely to be unreliable. Consequently, neither $\mathrm{SaO}_{2}$ nor sputum volume were included as outcome measures in this study.

An exacerbation was defined as an increase in lower respiratory tract symptoms requiring treatment with antibiotics in the opinion of the attending physician (MNP or SPC). The policy during the period of the treatment courses reviewed was as follows: all patients were maintained on oral antistaphylococcal agents; mild exacerbations (i.e. a minor increase in symptoms and/or a slight reduction in $\mathrm{FEV}_{1}$ or $\mathrm{FVC}$ ) were treated with oral ciprofloxacin and more severe exacerbations with intravenous antipseudomonal antibiotics. Patients were selected for home intravenous therapy if they were considered compliant enough to perform regular physiotherapy at home, and were able to reconstitute and administer intravenous antibiotics with adequate sterile technique. All patients spent 2-3 days in hospital before their first course of home therapy for tuition in these techniques. Each treatment course lasted approximately 2 weeks. In those patients without TIVAS an intravenous long-line was inserted in the antecubital fossa for home treatments.

All patients, whether at home or in hospital, were treated with two antipseudomonal antibiotics, based on the sensitivities of the most recent sputum culture. Where aminoglycosides were prescribed, doses were adjusted according to blood levels. Prophylactic nebulized antipseudomonal antibiotics were discontinued, but oral antistaphylococcal agents continued during intravenous treatment. Hospital patients received supervised physiotherapy twice daily, whilst patients treated at home were encouraged to perform their own physiotherapy twice daily. Patients on home treatment attended the unit at the start, mid-point and end of the course, and performance of physiotherapy was assessed at these times. Corroboration of the patients' stated frequency of performing physiotherapy was not routinely sought from partners or relatives. Sputum samples were obtained for antibiotic sensitivity testing at each unit attendance (usually twice) in the home treatments, and twice weekly in hospital treatments.

\section{Analysis}

To avoid bias in the selection of treatments for comparison, all home treatments of pulmonary exacerbations hitherto performed by the unit were included in the analysis. This meant including multiple comparisons (up to 6) for some patients. Fifty one home/hospital treatment pairs in 25 patients (14 males with 28 admissions, and 11 females with 23 admissions) were compared. To correct for any bias which might arise from the incorporation of multiple treatment pairs for some patients, the (post-treatment - pretreatment) difference for each variable was analysed using a mixed crossed/ nested design, with terms for patients, treatment pairs within patients, place (i.e. home or hospital treatment), and patient $\times$ place interaction. The magnitude of the changes observed with treatment is likely to be dependent on the absolute pretreatment values, and, therefore, analysis of covariance was performed, with the pretreatment values treated as covariates. Adjusted means were calculated to predict the mean change for a pretreatment value common to both hospital and home groups.

\section{Results}

There were no significant differences in pretreatment patient characteristics between the home and hospital groups (table 1).

Frequency and dosage of antibiotic usage are shown in table 2. There was a total of four adverse reactions to administered antibiotics, two in each treatment group, all consisting of mild skin rashes, which subsided with withdrawal of the offending antibiotic (imipenem, tobramycin, and azlocillin twice). One rash in each group occurred early in the treatment course, necessitating a change of antibiotic. Antibiotics were changed on the basis of resistant $P$. aeruginosa isolates from sputum culture in one home treatment and in 19

Table 1. - Pretreatment patient characteristics

\begin{tabular}{lll}
\hline & Home & Hospital \\
\hline Age yrs & $21 \pm 5$ & $22 \pm 3$ \\
Height for age \% pred & $99 \pm 4$ & $99 \pm 5$ \\
Weight for age \% pred & $85 \pm 12$ & $85 \pm 11$ \\
Weight for height \% pred $_{\text {FEV }_{1} \% \text { pred }}$ & $87 \pm 9$ & $87 \pm 9$ \\
FVC \% pred & $39 \pm 16$ & $40 \pm 17$ \\
Shwachman-Kulczyki score & $66 \pm 21$ & $65 \pm 20$ \\
Northern chest X-ray & $56 \pm 11$ & $54 \pm 10$ \\
score & $13 \pm 4$ & $14 \pm 3$ \\
\end{tabular}

Data are presented as mean \pm SD. $\mathrm{FEV}_{1}$ : forced expiratory volume in one second; FVC: forced vital capacity. 
Table 2. - Frequency of antibiotic administration and dosage schedule

\begin{tabular}{|c|c|c|c|}
\hline & $\begin{array}{l}\text { Times used in } \\
\text { home treatment }\end{array}$ & $\begin{array}{l}\text { Times used in } \\
\text { hospital treatment }\end{array}$ & Total dose $\cdot$ day $^{-1}$ \\
\hline Piperacillin & 9 & 11 & $600 \mathrm{mg} \cdot \mathrm{kg}^{-1} \max 16 \mathrm{~g}$ \\
\hline Azlocillin & 11 & 15 & $600 \mathrm{mg} \cdot \mathrm{kg}^{-1} \max 15 \mathrm{~g}$ \\
\hline Tobramycin & 31 & 36 & $10 \mathrm{mg} \cdot \mathrm{kg}^{-1}$ \\
\hline Ceftazidime & 26 & 23 & $150 \mathrm{mg} \cdot \mathrm{kg}^{-1} \max 6 \mathrm{~g}$ \\
\hline Aztreonam & 20 & 22 & $200 \mathrm{mg} \cdot \mathrm{kg}^{-1} \quad \max 7.5 \mathrm{~g}$ \\
\hline Imipenem & 3 & 10 & $1.5 \mathrm{~g}$ \\
\hline Colistin & 4 & 4 & 6 megaunits \\
\hline Total & 104 & 122 & \\
\hline
\end{tabular}

All antibiotics were administered in three divided doses, except piperacillin, given in four divided doses, and ceftazidime, given as a single infusion. In practice, the great majority of patients received the maximum allowable dose, where applicable. The tobramycin dose was adjusted to give $30 \mathrm{~min}$ postdose blood trough levels $<2 \mathrm{mg} \cdot l^{-1}$, and peak levels $10-12 \mathrm{mg} \cdot l^{-1}$.

hospital treatments. Mean duration of treatment was similar in the two groups (home 14.1 days, hospital 16.7 days).

The adjusted mean change with treatment for each variable is shown in table 3 . Each entry includes only treatment pairs for which all of the four data points were available for the variable in question. For each pair of treatments, the height differed between home and hospital by less than the measurement error $(1 \mathrm{~cm})$ in 48 cases. In the remaining three, it was between 1-3 $\mathrm{cm}$. Hence, expressing change in weight as absolute weight in kilograms, percentage predicted weight for height, or body mass index are equivalent in terms of statistical outcome, except that rounding errors may be introduced in the latter two methods. For this reason, and also because absolute weight gain is likely to be the measure of effective dietary intervention used in most units in the acute setting, the change in weight is expressed here in kilograms.

The only variable to show a significant difference between home and hospital "improvement achieved with treatment" was the total white cell count.

Table 3. - Baseline values and adjusted mean improvement for home and hospital treatments

\begin{tabular}{|c|c|c|c|c|c|}
\hline & $\mathrm{n}$ & $\begin{array}{c}\text { Home } \\
\text { baseline* }\end{array}$ & $\begin{array}{l}\text { Hospital } \\
\text { baseline* }\end{array}$ & $\begin{array}{c}\text { Home } \\
\text { adjusted mean } \\
\text { improvement }\end{array}$ & $\begin{array}{c}\text { Hospital } \\
\text { adjusted mean } \\
\text { improvement }\end{array}$ \\
\hline PEFR $l \cdot \min ^{-1}$ & 41 & $\begin{array}{c}350 \\
310-400\end{array}$ & $\begin{array}{c}350 \\
305-400\end{array}$ & $\begin{array}{c}66.1 \\
(6.8)\end{array}$ & $\begin{array}{l}57.5 \\
(16.6)\end{array}$ \\
\hline $\mathrm{FVC} l$ & 49 & $\begin{array}{c}2.44 \\
2.13-2.95\end{array}$ & $\begin{array}{c}2.35 \\
2.06-2.90\end{array}$ & $\begin{array}{c}0.567 \\
(0.049)\end{array}$ & $\begin{array}{c}0.644 \\
(0.046)\end{array}$ \\
\hline $\mathrm{FEV}_{1} l$ & 49 & $\begin{array}{c}1.25 \\
1.08-1.67\end{array}$ & $\begin{array}{c}1.26 \\
1.01-1.63\end{array}$ & $\begin{array}{c}0.456 \\
(0.050)\end{array}$ & $\begin{array}{c}0.403 \\
(0.054)\end{array}$ \\
\hline White cell count $10^{9}$ cells $\cdot l^{-1}$ & 47 & $\begin{array}{c}11.6 \\
10.1-13.4\end{array}$ & $\begin{array}{c}12.4 \\
9.2-16.5\end{array}$ & $\begin{array}{l}-3.64 * * \\
(0.38)\end{array}$ & $\begin{array}{l}-4.72 * * \\
(0.36)\end{array}$ \\
\hline Neutrophil count $10^{9} \mathrm{cells} \cdot l^{-1}$ & 38 & $\begin{array}{c}8.0 \\
6.9-9.9\end{array}$ & $\begin{array}{c}8.7 \\
6.3-13.1\end{array}$ & $\begin{array}{l}-3.07 \\
(0.46)\end{array}$ & $\begin{array}{l}-4.00 \\
(0.46)\end{array}$ \\
\hline Plasma viscosity $\mathrm{mPa}$ & 39 & $\begin{array}{c}1.86 \\
1.80-2.00\end{array}$ & $\begin{array}{c}1.89 \\
1.80-2.00\end{array}$ & $\begin{array}{l}-0.11 \\
(0.02)\end{array}$ & $\begin{array}{l}-0.11 \\
(0.02)\end{array}$ \\
\hline Total IgG $\mathrm{mg} \cdot l^{-1}$ & 39 & $\begin{array}{c}18.7 \\
15.5-21.1\end{array}$ & $\begin{array}{c}17.1 \\
15.3-20.2\end{array}$ & $\begin{array}{l}-0.1 \\
(0.4)\end{array}$ & $\begin{array}{l}-0.5 \\
(0.4)\end{array}$ \\
\hline $\mathrm{CRP} \mathrm{mg} \cdot l^{-1}$ & 39 & $\begin{array}{c}17 \\
10-40\end{array}$ & $\begin{array}{c}26 \\
11-45\end{array}$ & $\begin{array}{r}-19.5 \\
(2.2)\end{array}$ & $\begin{array}{r}-22.2 \\
(2.2)\end{array}$ \\
\hline Northern chest X-ray score & 49 & $\begin{array}{c}13 \\
11-15\end{array}$ & $\begin{array}{c}15 \\
11-16\end{array}$ & $\begin{array}{l}-1.3 \\
(0.2)\end{array}$ & $\begin{array}{l}-1.4 \\
(0.2)\end{array}$ \\
\hline Weight $\mathrm{kg}$ & 50 & $\begin{array}{c}52.9 \\
49.8-58.0\end{array}$ & $\begin{array}{c}52.4 \\
47.8-56.6\end{array}$ & $\begin{array}{c}0.79 \\
(0.21)\end{array}$ & $\begin{array}{c}0.51 \\
(0.28)\end{array}$ \\
\hline Clinical score & 47 & $\begin{array}{c}9 \\
8-11\end{array}$ & $\stackrel{9}{7-12}$ & $\begin{array}{l}-4.2 \\
(0.3)\end{array}$ & $\begin{array}{l}-4.6 \\
(0.2)\end{array}$ \\
\hline $\begin{array}{l}\text { Shwachman-Kulczyki } \\
\text { score }\end{array}$ & 32 & $\begin{array}{c}55 \\
50-60\end{array}$ & $\begin{array}{c}53 \\
46-55\end{array}$ & $\begin{array}{c}9.7 \\
(0.9)\end{array}$ & $\begin{array}{c}8.6 \\
(0.9)\end{array}$ \\
\hline
\end{tabular}

*: data are presented as median and quartiles; $\dagger$ : data are presented as adjusted mean and SEM in parenthesis. PEFR: peak expiratory flow rate; FVC: forced vital capacity; $\mathrm{FEV}_{1}$ : forced expiratory volume in one second; IgG: immunoglobulin G; CRP: C-reactive protein. **: $\mathrm{p}<0.05$ between improvement at home and improvement in hospital (two-tailed two sample t-test). 


\section{Discussion}

With the exception of the total white cell count, all the measured variables improved to a similar degree, with no significant differences between the home- and hospital-treated groups. Although the difference in improvement in total white cell count reached statistical significance, the magnitude of the difference was small and not clinically relevant. The improvement in neutrophil count did not differ between the two groups. The Shwachman-Kulczyki and clinical scores both involve some subjective input, and scores were not all assigned by the same person. Interobserver variability would tend to obscure any real differences in scores in this situation. The same caveat applies to the chest X-ray scores. However, the peripheral markers of inflammation, spirometry and weight are wholly objective, and were very similar between the two groups.

Treatment of an acute exacerbation of cystic fibrosis involves three basic modalities: antibiotics, the maximizing of calorie intake, and physiotherapy. Concerns with home therapy are that prescribed antibiotics will not be administered properly, that calorie intake will suffer without daily encouragement, and that physiotherapy will not be as effective in the absence of a professional physiotherapist (particularly as many patients on home treatment continue with work or education, with less time available for physiotherapy than would be the case in hospital). Deficiencies in these three areas in home therapy would be expected to yield differences in markers of inflammation, weight gain, and spirometry, respectively, between home and hospital groups. The lack of such differences in our series implies that all three treatment modalities were adequate in the home setting. Antibiotic therapy was modified on the basis of changing sensitivity of isolated organisms in 19 hospital treatments, compared with only one home treatment. This is partly explained by the increased frequency of bacteriological monitoring in the hospital group, and probably also because of the greater ease of instituting a change of antibiotic in the hospital setting. Despite this, outcome was similar in the two groups, raising a doubt about the usefulness of intensive monitoring of Pseudomonal sensitivity testing during antibiotic therapy. Clearly, a separate, prospective study would be needed to answer this question.

The ideal way to determine the relative efficacy of home and hospital treatment would be with a prospective study. However, in an adult population randomization would be problematic. Patients with exacerbations complicated by pneumothorax, extensive haemoptysis, etc. (more common in the adult age group) clearly require hospitalization. In addition, whether a particular course of treatment takes place in the home or in hospital is often determined by psychosocial factors. The limitations imposed by the retrospective nature of our study are to some extent ameliorated by drawing on data that have been routinely incorporated into a database. The main concern is that home and hospital treatments might not have been instituted under the same circumstances, with the more ill patients receiving hospital care preferentially. In fact, baseline, pretreatment values were very similar between the two groups. In addition, treating the pretreatment values as covariates renders the adjusted mean changes independent of the absolute pretreatment values, and differences in their magnitude then reflect differences in the treatments employed.

Several previous studies have demonstrated the feasibility [9, 10], and cost-effectiveness [11-14], of home intravenous antibiotic treatment in cystic fibrosis. Clinical improvement with home therapy in appropriately selected patients has been well-demonstrated [15-18]. However, there is only one published controlled comparison of outcome in home versus hospital therapy in cystic fibrosis [19]. In this study, FVC was found to improve to a significantly greater extent in hospital, as was arterial oxygen tension $\left(\mathrm{PaO}_{2}\right)$, but not the other measured variables, which included $\mathrm{FEV}_{1}$. The authors concluded, however, that these differences were probably explained by differences in the pretreatment values, with hospital-treated patients starting from lower values, and consequently having more potential for improvement. Our results support this interpretation for FVC, as the treatment of the baseline values as covariates in our study corrects for any possible bias which might have been introduced by the hospital-treated patients being more ill. No significant difference in improvement in FVC between home- and hospital-treated patients was seen in our study. Arterial blood gases are not routinely measured on our unit and, thus, were not available for analysis.

The optimum pattern of antibiotic therapy in cystic fibrosis is not known, but many centres are tending towards more frequent administration. In-patient treatment is inconvenient for patients, and an economic burden to both patient and health care provider. In our experience, most patients prefer home treatment, and a minority refuse any hospital treatment. Our results show that treatment of uncomplicated exacerbations is equally effective at home or in hospital, given proper patient selection and monitoring of the response to therapy.

\section{References}

1. Borregaard N. Bactericidal mechanisms of the human neutrophil. Scand J Haematol 1984; 32: 225-230.

2. Dasgupta MK, Lam J, Doruig G, et al. Prognostic implications of circulating immune complexes and Pseudomonas aeruginosa specific antibodies in cystic fibrosis. J Clin Lab Immunol 1987; 23: 25-30.

3. Pressler T, Mausa B, Jensen T, Pedersen SS, Hoiby N. Increased $\mathrm{IgG}_{2}$ and $\mathrm{IgG}_{3}$ concentration is associated with advanced Pseudomonas aeruginosa infection and poor pulmonary function in cystic fibrosis. Acta Paediatr Scand 1988; 77: 576-582.

4. Szaff M, Hoiby N, Flensborg EW. Frequent antibiotic therapy improves survival of cystic fibrosis patients with chronic Pseudomonas aeruginosa infection. Acta Paediatr Scand 1983; 72; 651-657.

5. Conway SP, Miller MG, Ramsden C, Littlewood JM. Intensive treatment of Pseudomonas chest infection in cystic fibrosis: a comparison of tobramycin and ticarcillin, and netilmicin and ticarcillin. Acta Paediatr Scand 1985; 74: 107-113. 
6. Shwachman H, Kulczyki LL. Long-term study of one hundred and five patients with cystic fibrosis. Am J Dis Child 1958; 96: 6-15.

7. Fletcher EC, Luckett RA, Miller T, Costarangos C, Kutka N, Fletcher JG. Pulmonary vascular haemodynamics in chronic lung disease patients with and without oxyhaemoglobin desaturation during sleep. Chest 1989; 95: 157-166.

8. Montgomery M, Wiebicke W, Bibi H, Pagtakhan RD, Pasterkamp H. Home measurement of oxygen saturation during sleep in patients with cystic fibrosis. Pediatr Pulmonol 1989; 7: 29-34.

9. Poretz DM, Eron LJ, Goldenberg RJ, et al. Intravenous antibiotic therapy in an out-patient setting. $J \mathrm{Am} \mathrm{Med}$ Assoc 1982; 248: 336-339.

10. Rehm SJ, Weinstein AJ. Home intravenous antibiotic therapy: a team approach. Ann Intern Med 1983; 99: 388-392.

11. Stiver HG, Telford GO, Mossey JM, et al. Intravenous antibiotic therapy at home. Ann Intern Med 1978; 89: 690-693.

12. Kind AC, Williams DN, Persons G, Gibson JA. Intravenous antibiotic therapy at home. Arch Intern Med 1979; 139: 413-415.
13. Stiver HG, Trosky SK, Cote DD, Oruck JL. Selfadministration of intravenous antibiotics: an efficient, cost-effective home care program. Can Med Assoc J 1982; 127: 207-211.

14. Kane RE, Jennison K, Wood C, Black PG, Herbst JH. Cost savings and economic considerations using home intravenous antibiotic therapy for cystic fibrosis patients. Pediatr Pulmonol 1988; 4: 84-89.

15. Winter RJD, George RJD, Deacock SJ, Shee CD, Geddes DM. Self-administered home intravenous antibiotic therapy in bronchiectasis and adult cystic fibrosis. Lancet 1984; i: 1338-1339.

16. Strandvik B, Hjelte L, Widen B. Home intravenous antibiotic treatment in cystic fibrosis. Scand J Gastroenterol 1988; 23 (Suppl. 143): 119-120.

17. Gilbert J, Robinson T, Littlewood JM. Home intravenous antibiotic treatment in cystic fibrosis. Arch Dis Child 1988; 63: 512-517.

18. Strandvik B, Hjelte L, Malmborg AS, Widen B. Home intravenous antibiotic treatment of patients with cystic fibrosis. Acta Pediatr 1992; 81: 340-344.

19. Donati MA, Guenette G, Auerbach H. Prospective controlled study of home and hospital therapy of cystic fibrosis pulmonary disease. J Pediatr 1987; 111: 28-33. 